\title{
Gender differences at presentation of idiopathic pulmonary fibrosis in Sweden
}

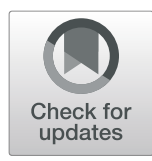

Dimitrios Kalafatis ${ }^{1}$, Jing Gao ${ }^{1}$, Ida Pesonen ${ }^{1,2}$, Lisa Carlson ${ }^{1,2}$, C. Magnus Sköld ${ }^{1,2}$ and Giovanni Ferrara ${ }^{1,2^{*}}$ (D)

\begin{abstract}
Background: Idiopathic pulmonary fibrosis (IPF) is a disease with poor prognosis mainly affecting males. Differences in clinical presentation between genders may be important both for the diagnostic work-up and for follow-up. In the present study, we therefore explored potential gender differences at presentation in a Swedish cohort of IPF-patients.

Methods: We studied patients included in the Swedish IPF- registry over a three-year period from its launch in 2014. A cross-sectional analysis was performed for data concerning demographics, lung function, 6- min walking test (6MWT) and quality of life (QoL) (King's Brief Interstitial Lung Disease (K-BILD) score).

Results: Three hundred forty- eight patients (250 (72\%) males, 98 (28\%) females, median age 72 years in both genders) were included in the registry during the study period. Smoking history ( $N=169$ (68\%) vs. $N=53(54 \%)$, $p<0.05$ ), baseline lung function (Forced vital capacity, \% of predicted (FVC\%): 68.9\% \pm 14.4 vs. $73.0 \% \pm 17.7, p<0.05$; Total lung capacity, \% of predicted (TLC\%): $62.2 \% \pm 11.8$ vs. $68.6 \% \pm 11.3 \%, p<0.001$ ) were significantly different at presentation between males and females, respectively. Comorbidities such as coronary artery disease (OR: 3.5-95\% Cl: 1.6-7.6) and other cardiovascular diseases (including atrial fibrillation and heart failure) (OR: 3.8-95\% Cl: 1.9-7.8) also showed significant differences between the genders. The K- BILD showed poor quality of life, but no difference was found between genders in total score ( $54 \pm 11$ vs. $54 \pm 10, p=0.61$ in males vs. females, respectively).

Conclusions: This study shows that female patients with IPF have a more preserved lung function than males at inclusion, while males have a significant burden of cardiovascular comorbidities. However, QoL and results on the $6 \mathrm{MWT}$ did not differ between the groups. These gender differences may be of importance both at diagnosis and follow- up of patients with IPF.
\end{abstract}

Keywords: Idiopathic pulmonary fibrosis, Gender perspective, Interstitial lung disease, Comorbidities, Registry, KBILD

\section{Background}

Idiopathic pulmonary fibrosis (IPF) is a chronic and progressive disease of unknown etiology limited to the lungs resulting in an irreversible loss of pulmonary function, and, finally, in respiratory failure and death $[1,2]$. While results from epidemiological studies have varied due to the different methodologies and diagnostic criteria used, the estimated prevalence of 18-63 cases per 100,000 and a median survival of 3-5years, makes IPF the most common and deadly form of the idiopathic interstitial pneumonias (IIP) [3-5].

\footnotetext{
* Correspondence: Giovanni.Ferrara@ki.se; ferrara@ualberta.ca

${ }^{1}$ Respiratory Medicine Unit, Department of Medicine Solna, Karolinska Institutet, Stockholm, Sweden

${ }^{2}$ Department of Respiratory Medicine and Allergy, Karolinska University Hospital, Stockholm, Sweden
}

In clinical practice, patients with IPF also present with a large number of comorbidities such as coronary artery disease, arterial hypertension, gastroesophageal reflux, sleep apnea, chronic obstructive pulmonary disease (COPD), asthma and diabetes among others [6], and will often die due to reasons other than IPF $[7,8]$. Furthermore, the optimal management of these conditions and their relevance for the prognosis of patients with IPF is still unclear.

In recent years, the gender perspective has become evident in diseases such as COPD [9] or lung cancer [10]. It is well known that IPF is more frequent among males than females [1], but very little is known about potential differences in presentation of the disease and its comorbidities between the genders. Gender was included in a multidimensional index and scoring system

(c) The Author(s). 2019 Open Access This article is distributed under the terms of the Creative Commons Attribution 4.0 International License (http://creativecommons.org/licenses/by/4.0/), which permits unrestricted use, distribution, and 
for IPF patients, the Gender- Age- Physiology (GAP) score, with males showing a higher risk of dying compared to females [11], but the mechanisms leading to this difference are still poorly characterized. Gender differences may have important implications in the diagnosis, treatment and prognosis of IPF [12] and a better understanding of these differences may also give us new clues about disease etiology.

The main objective of this paper was therefore to explore the gender differences in the clinical features of IPF.

\section{Methods}

\section{Collection of data}

The Swedish IPF Registry was started in 2014. A webbased platform (Granitics Unify Med, Granitics Ltd., Espoo, Finland), allows the registration of demographics, lung function, radiology, health related quality of life (QoL) (assessed with the King's Brief Interstitial Lung Disease Questionnaire (K-BILD)) [13], ongoing treatments, side- effects and outcomes such as death and lung transplantation at the time of inclusion in the registry and during the follow-up. The platform is currently implemented in 22 respiratory medicine units in the country, including all the main university and reference hospitals. This accounts for approximately $60 \%$ of the units with at least one respiratory specialist in service. To be included in the registry, patients had to fulfill the diagnostic criteria for the diagnosis of IPF according to national and international guidelines [1, 14]. Patients are eligible for inclusion in the registry if they have a confirmed diagnosis of IPF by a specialist in respiratory medicine either at an university hospital or a local hospital, and have provided a written informed consent prior to inclusion. No explicit exclusion criteria are defined, but diagnoses other than IPF are not included. Patients were considered incident cases (diagnosis within 6 months from consent) and prevalent if the duration of disease exceeded 6 months.

To explore potential gender differences at the time of inclusion in the registry, a cross-sectional analysis was performed from September 2014 to December 2017 for data concerning demographics, lung function, 6- $\mathrm{min}$ walking test (6MWT), and QoL (K-BILD score). Data on comorbidities were mostly self-reported by the patient.

\section{Statistical analyses}

Continuous variables are presented as mean \pm standard deviation $(\mathrm{M} \pm \mathrm{SD})$ or median and range or lower and upper quartile. Categorical variables are presented as proportions of the total population. Two sample t- test was used when appropriate, and non- parametric data was analyzed with the Mann- Whitney test. Results were considered statistically significant if $p<0.05$. Subgroup analyses for gender were performed. Differences in frequency of comorbidities between genders were expressed with Odds ratios (OR) with 95\% confidence interval. Study subjects were pooled to analyze the correlations between quality of life, with K- BILD total score as the dependent factor and clinical variables (age, $\mathrm{FVC} \%$, number of comorbidities, $\mathrm{BMI}, \mathrm{FEV}_{1} \%$ ) in males and females as independent factors. No replacement nor extrapolation of missing values was performed. Univariate analyses included only available variables, while missing values in the multivariable model were automatically removed by the statistical software. Number of available data for each variable is included in respective table. Statistical analyses were performed using the statistical software Wizard Pro (version 1.9.22 (240) @Evan Miller) and SPSS 25.0 (IBM Corporation, Armonk, NY, USA).

The study was approved in August 2014 by the Stockholm's Regional Ethical Committee (Ref. No. 2014/ 1202-31/4 and Ref No. 2018/1449-31/1). All patients were included in the registry upon signing a written consent before inclusion.

\section{Results \\ Demographics}

Twenty-two respiratory units in the country $(61 \%$ of the country's hospitals with a respiratory disease active service) reported data from 348 IPF patients to the Swedish IPF registry during the study period. Demographics at the time of inclusion in the IPF registry are reported in Table 1. Sixty- seven patients $(19 \%)$ were on anti- fibrotic treatment at inclusion, of whom 14 where incident cases and 53 prevalent.

Significantly more ex- smokers were reported among males $(n=169$ (68\%); females: $n=53(54 \%) ; p=0.020)$, as well as higher pack years compared to females $(24.8 \pm 15.1$ in male vs. $17.8 \pm 13.3$ in female, $p=0.005)$ (Table 2). Among ex-smokers, diagnosis of IPF was confirmed more than two decades after smoking cessation in both genders ( $25 \pm 15$ years (142 patients) and $24 \pm 13$ years (46 patients), $p=0.796$ in males and females, respectively).

\section{Lung function and six- minute walk test}

Forced vital capacity, \% of predicted (FVC\%) and total lung capacity, \% of predicted (TLC\%), were significantly lower in males compared to females (Table 3). When the patients were divided by smoking history, male exsmokers had lower FVC\%, TLC\% and DLCO\%, while no differences were found in never- smokers. Male never-smokers had a longer walking distance (6MWD) than females $(p=0.030)$. No gender- or smoking related difference in other parameters of the 6MWT, including saturation level at rest $(\mathrm{B}-\mathrm{SpO} 2)$ and during/after test (L-SpO2) was observed. 
Table 1 Baseline variables of the included patients

\begin{tabular}{|c|c|}
\hline Baseline variables & Total \\
\hline \multicolumn{2}{|l|}{ IPF-patients $(N=348)$} \\
\hline Incident / Prevalent (N, \%) & $182(52.3) / 166(47.7)$ \\
\hline Gender (male /female) (N, \%) & $250(71.8) / 98(28.1)$ \\
\hline Age (Median, range) & $72.0(46-88)$ \\
\hline $\mathrm{BMI}(\mathrm{M} \pm \mathrm{SD})$ & $27.1 \pm 4.2$ \\
\hline \multicolumn{2}{|l|}{ Smoking habit $(N=348)$} \\
\hline Never smoker (N, \%) & $103(29.6)$ \\
\hline Ex-smoker (N, \%) & $222(63.8)$ \\
\hline Packyear $(M \pm S D)(E x-s m o k e r, n=160)$ & $23.0 \pm 15.0$ \\
\hline Smoker (N, \%) & $12(3.5)$ \\
\hline Missing info $(\mathrm{N}, \%)$ : & $11(3.2)$ \\
\hline \multicolumn{2}{|l|}{ Lung function } \\
\hline FVC\% $(M \pm S D)(N=287)$ & $70.2 \pm 15.6$ \\
\hline $\mathrm{FEV}_{1} \%(\mathrm{M} \pm \mathrm{SD})(N=307)$ & $76.1 \pm 16.6$ \\
\hline $\mathrm{TLC} \%(\mathrm{M} \pm \mathrm{SD})(N=193)$ & $63.9 \pm 12.0$ \\
\hline $\mathrm{DLCO} \%(\mathrm{M} \pm \mathrm{SD})(N=221)$ & $46.2 \pm 13.9$ \\
\hline \multicolumn{2}{|l|}{ 6-WMT $(N=198)$} \\
\hline 6-WMD $(M \pm S D, m)$ & $422 \pm 124$ \\
\hline B-SpO2\% (M $\pm S D, \%)$ & $95.8 \pm 2.3$ \\
\hline L-SpO2\% (M $\pm S D, \%)$ & $86.1 \pm 6.7$ \\
\hline \multicolumn{2}{|l|}{ Comorbidity $(N=348)$} \\
\hline Arterial hypertension ( $\mathrm{N}, \%)$ & $115(33.0)$ \\
\hline Gastroesophageal reflux (N, \%) & $113(32.5)$ \\
\hline Other cardiovascular ${ }^{\mathrm{a}}(\mathrm{N}, \%)$ & $86(24.7)$ \\
\hline Coronary heart disease ( $N, \%)$ & $67(19.3)$ \\
\hline Diabetes (N, \%) & $52(14.9)$ \\
\hline Cancer (N, \%) & $33(9.5)$ \\
\hline Thyroid diseases $^{\mathrm{b}}(\mathrm{N}, \%)$ & $22(6.3)$ \\
\hline Sleep apnea (N, \%) & $22(6.3)$ \\
\hline Asthma (N, \%) & $15(4.3)$ \\
\hline $\operatorname{COPD}(\mathrm{N}, \%)$ & $10(2.9)$ \\
\hline Osteoporosis (N, \%) & $6(1.7)$ \\
\hline K-BILD $(N=292)$ & $53.7 \pm 10.7$ \\
\hline Anti-fibrotic treatment (N, \%) & $67(19.3)$ \\
\hline Time from diagnosis to consent (median, Q1- Q3) (months) & 4 (Q1:0; Q3: 26) \\
\hline
\end{tabular}

$N$ number(s), $M$ mean, SD standard deviation, BMI body mass index, FVC\% forced vital capacity, \% of expected, FEV $1 \%$ forced expiratory volume in first second, \% of expected, $T L C \%$ total lung capacity, \% of expected, DLCO\% \% diffusing capacity for carbon monoxide, $6 M W D 6$ min walking distance, $B$-SpO2\% Saturation level for oxygen, at rest, L-SpO2\% Saturation level for oxygen, lowest during/after test, K-BILD King's Brief Interstitial Lung Disease questionnaire ${ }^{a}$ Other cardiovascular disease: Atrial fibrillation and Heart failure

${ }^{\text {b}}$ Thyroid diseases: hypo-/hyperthyroidism

\section{Quality of life}

The K-BILD total score and its three domain scores for psychological, breathlessness and chest symptoms, were available for 292 (84\%, 210 males and 82 females) of the patients. No differences were seen between genders in total K-BILD score, and in the domains of psychological and breathlessness scores $(p>0.05)$ (Table 3). However, the K-BILD domain for chest symptoms were higher in male never- smokers when compared to female neversmokers $(p=0.030)$ (Table 3$)$. 
Table 2 Demographics of included patients divided by gender

\begin{tabular}{lll}
\hline & Male & Female \\
\hline IPF-patients (N, \% in total) & $250(71.8)$ & $98(28.1)$ \\
Age (Median, range) & $72(46-88)$ & $72(56-84)$ \\
BMI (M \pm SD) & $27.0 \pm 3.74$ & $27.3 \pm 5.18$ \\
Smoking status & & \\
$\quad$ Never smoker (N, \% in gender) & $64(25.6)$ & $39(39.8)$ \\
Ex-smoker (N, \% in gender) & $169(67.6)^{*}$ & $53(54.1)$ \\
Smoker (N, \% in gender) & $7(2.8)$ & $5(5.1)$ \\
$\quad$ Missing info (N, \% in gender) & $10(4.0)$ & $1(1.0)$ \\
Packyear in ex-smokers (M $\pm \mathrm{SD})$ & $24.8 \pm 15.1^{*}$ & $17.8 \pm 13.3$ \\
\hline
\end{tabular}

$N$ number(s), $M$ mean, $S D$ standard deviation, $B M I$ body mass index ${ }^{*} p<0.05$, male vs. female

\section{Comorbidities}

Arterial hypertension and gastroesophageal reflux were the two most common comorbidities reported in the whole cohort (Table 1). The frequency of single and multiple comorbidities is presented in Table 4. Multiple comorbidities were observed in 193 males (77\% of total males) and 78 females (80\%). Coronary heart disease and other cardiovascular diseases (atrial fibrillation and heart failure) were significantly more prevalent among males, while thyroid diseases, asthma and osteoporosis were more prevalent in females. Sub- analyses by gender and smoking history showed that coronary heart disease remained more prevalent in both never- and ex-smoking males compared to females, while gastroesophageal reflux and asthma were more frequent in female neversmokers. Among ex- smoking females, a difference in the prevalence of thyroid diseases was observed. Male ex- smokers showed a higher prevalence of other cardiovascular diseases.

\section{Impact factors on K-BILD total score}

Multivariate analysis showed $\mathrm{FVC} \%$ to be an independent predictor for K-BILD total score in males and in total, whereas none of the selected clinical variables were independent predictors for K-BILD total score in females (Table 5).

\section{Discussion}

This paper describes a cohort of IPF- patients included in the Swedish IPF registry in its first 3 years of activity. The study aimed to specifically characterize gender differences in terms of demographics, lung function tests, QoL and comorbidities. The data on demographics, lung function and 6MWT in the whole cohort were similar to what has been reported in other registry studies [15-17]. As in the German INSIGHTS- IPF registry [16], our study showed that IPF occurs approximately 20 years

Table 3 Lung function parameters, 6MWT and K-BILD results divided by smoking status and gender

\begin{tabular}{|c|c|c|c|c|c|c|}
\hline & \multicolumn{2}{|l|}{ Total } & \multicolumn{2}{|c|}{ Never smoker } & \multicolumn{2}{|l|}{ Ex-smoker } \\
\hline & Male & Female & Male & Female & Male & Female \\
\hline \multicolumn{7}{|l|}{ Lung function } \\
\hline \multirow[t]{2}{*}{ FVC\% $(N=287)$} & $N=198$ & $N=89$ & $N=50$ & $N=37$ & $N=139$ & $N=47$ \\
\hline & $68.9 \pm 14.4^{*}$ & $73.0 \pm 17.7$ & $69.7 \pm 18.0$ & $66.8 \pm 16.8$ & $68.7 \pm 12.7^{* *}$ & $75.8 \pm 16.3$ \\
\hline \multirow[t]{2}{*}{ FEV1\% $(N=307)$} & $N=215$ & $N=92$ & $N=54$ & $N=38$ & $N=152$ & $N=49$ \\
\hline & $76.1 \pm 16.1$ & $76.0 \pm 17.7$ & $76.8 \pm 18.5$ & $71.3 \pm 18.9$ & $76.4 \pm 14.6$ & $78.6 \pm 16.1$ \\
\hline \multirow[t]{2}{*}{ TLC\%, $(N=193)$} & $N=141$ & $N=52$ & $N=35$ & $N=21$ & $N=103$ & $N=31$ \\
\hline & $62.2 \pm 11.8^{*}$ & $68.6 \pm 11.3$ & $61.8 \pm 11.9$ & $64.4 \pm 10.8$ & $62.0 \pm 11.7^{* * *}$ & $71.3 \pm 11.0$ \\
\hline \multirow[t]{2}{*}{$\operatorname{DLCO} \%(N=221)$} & $N=158$ & $N=63$ & $N=39$ & $N=25$ & $N=113$ & $N=35$ \\
\hline & $45.2 \pm 13.6$ & $48.8 \pm 14.4$ & $49.7 \pm 14.1$ & $46.7 \pm 14.2$ & $43.8 \pm 13.3^{*}$ & $49.3 \pm 13.3$ \\
\hline $6 \mathrm{WMT}(N=198)$ & $N=139$ & $N=59$ & $N=35$ & $N=22$ & $N=102$ & $N=35$ \\
\hline $6 \mathrm{MWD},(\mathrm{M} \pm \mathrm{SD}, \mathrm{m})$ & $427 \pm 128$ & $411 \pm 113$ & $439 \pm 136^{*}$ & $355 \pm 140$ & $426 \pm 125$ & $446 \pm 79$ \\
\hline B-SpO2\% (M \pm SD, \%) & $95.7 \pm 2.30$ & $95.9 \pm 2.3$ & $95.4 \pm 2.0$ & $95.8 \pm 2.7$ & $95.8 \pm 2.4$ & $95.9 \pm 2.1$ \\
\hline L-SpO2\% (M \pm SD, \%) & $85.9 \pm 6.44$ & $86.6 \pm 7.4$ & $85.8 \pm 6.5$ & $88.0 \pm 8.5$ & $85.8 \pm 6.4$ & $85.7 \pm 6.6$ \\
\hline K-BILD $(N=292)$ & $N=210$ & $N=82$ & $N=55$ & $N=33$ & $N=146$ & $N=44$ \\
\hline Psychological & $55.1 \pm 16.6$ & $54.9 \pm 15.6$ & $57.8 \pm 16.1$ & $53.0 \pm 13.2$ & $54.4 \pm 17.0$ & $55.6 \pm 17.7$ \\
\hline Breathlessness and activities & $36.8 \pm 18.7$ & $40.0 \pm 17.1$ & $38.5 \pm 21.9$ & $34.5 \pm 13.7$ & $37.2 \pm 17.1$ & $41.3 \pm 16.7$ \\
\hline Chest symptoms & $64.1 \pm 21.7$ & $66.0 \pm 22.9$ & $71.4 \pm 21.4^{*}$ & $60.6 \pm 20.4$ & $62.5 \pm 21.4$ & $67.9 \pm 24.2$ \\
\hline Total & $53.6 \pm 10.9$ & $54.3 \pm 10.1$ & $55.5 \pm 11.1$ & $51.8 \pm 7.8$ & $53.3 \pm 11.0$ & $55.1 \pm 11.3$ \\
\hline
\end{tabular}

$M$ mean, SD standard deviation, FVC\% forced vital capacity, \% of expected, FEV1\% forced expiratory volume in first second, \% of expected, TLC\% total lung capacity, \% of expected, DLCO\% \% diffusing capacity for carbon monoxide, $6 M W D 6$ min walking distance, B-SpO2\% Saturation level for oxygen, at rest, L-SpO2\% Saturation level for oxygen, lowest during/after test, $K$-BILD King's Brief Interstitial Lung Disease questionnaire

*: $p<0.05,{ }^{* *} p<0.01,{ }^{* * *} p<0.001$ males vs. females 
Table 4 Frequency of comorbidities reported at inclusion

\begin{tabular}{|c|c|c|c|c|c|c|c|c|c|}
\hline & \multicolumn{2}{|l|}{ Total } & \multirow[b]{3}{*}{ OR $(95 \% \mathrm{Cl})$} & \multicolumn{2}{|c|}{ Never smoker } & \multirow[b]{3}{*}{ OR $(95 \% \mathrm{Cl})$} & \multicolumn{2}{|l|}{$\underline{\text { Ex-smoker }}$} & \multirow[b]{3}{*}{ OR (95\%Cl) } \\
\hline & Male & Female & & Male & Female & & Male & Female & \\
\hline & $(N=250)$ & $(N=98)$ & & $(N=64)$ & $(N=39)$ & & $(N=169)$ & $(N=53)$ & \\
\hline \multicolumn{10}{|l|}{ Single Comorbidity } \\
\hline Arterial hypertension ( $\mathrm{N}, \%)$ & $84(34)$ & $31(32)$ & $1.09(0.66-1.80)$ & $18(28)$ & $8(21)$ & $1.52(0.59-3.92)$ & $62(37)$ & $20(38)$ & $0.96(0.51-1.81)$ \\
\hline Gastroesophageal reflux (N, \%) & $74(30)$ & $39(40)$ & $0.64(0.39-1.04)$ & $16(25)$ & $20(51)$ & $0.32(0.14-0.74)$ & $55(33)$ & $17(32)$ & $1.02(0.53-1.98)$ \\
\hline Other cardiovascular ${ }^{\mathrm{a}}(\mathrm{N}, \%)$ & $76(30)$ & $10(10)$ & $3.84(1.89-7.80)$ & $18(28)$ & $5(13)$ & $2.70(0.90-7.88)$ & $54(32)$ & $5(9)$ & $4.51(1.70-12.0)$ \\
\hline Coronary heart disease $(\mathrm{N}, \%)$ & $59(24)$ & $8(8)$ & $3.48(1.59-7.58)$ & $14(22)$ & $1(3)$ & $10.6(1.34-84.5)$ & $43(25)$ & $6(11)$ & $2.70(1.07-6.70)$ \\
\hline Diabetes (N, \%) & $38(15)$ & $14(14)$ & $1.08(0.55-2.09)$ & $6(9)$ & $3(8)$ & $1.24(0.29-5.28)$ & $30(18)$ & $10(19)$ & $0.93(0.42-2.05)$ \\
\hline Cancer (N, \%) & $20(8)$ & $13(13)$ & $0.57(0.27-1.19)$ & $4(6)$ & $5(13)$ & $0.45(0.11-1.80)$ & $15(9)$ & $7(13)$ & $0.64(0.25-1.66)$ \\
\hline Thyroid diseases ${ }^{\mathrm{b}}(\mathrm{N}, \%)$ & $11(4)$ & $11(11)$ & $0.36(0.15-0.87)$ & $4(6)$ & $2(5)$ & $1.23(0.22-7.07)$ & $6(4)$ & $8(15)$ & $0.21(0.07-0.63)$ \\
\hline Sleep apnea $(\mathrm{N}, \%)$ & $18(7)$ & $4(4)$ & $1.82(0.60-5.53)$ & $4(6)$ & $3(8)$ & $0.80(0.17-3.78)$ & $13(8)$ & $1(2)$ & $4.33(0.55-33.9)$ \\
\hline Asthma (N, \%) & $5(2)$ & $10(10)$ & $0.18(0.06-0.54)$ & $3(5)$ & $8(21)$ & $0.19(0.05-0.77)$ & $2(1)$ & $2(4)$ & $0.31(0.04-2.22)$ \\
\hline $\operatorname{COPD}(\mathrm{N}, \%)$ & $8(3)$ & $2(2)$ & $1.59(0.33-7.61)$ & $0(0)$ & $0(0)$ & - & $7(4)$ & $1(2)$ & $2.25(0.27-18.7)$ \\
\hline Osteoporosis (N, \%) & $1(0.4)$ & $5(5)$ & $0.10(0.01-0.65)$ & $1(2)$ & $3(8)$ & $0.19(0.02-1.90)$ & $0(0)$ & $2(4)$ & $0.06(0.003-1.30)$ \\
\hline \multicolumn{10}{|l|}{ Multiple comorbidities } \\
\hline 1- comorbidity (N, \%) & $77(31)$ & $31(32)$ & $0.96(0.58-1.59)$ & $15(23)$ & $14(36)$ & $0.69(0.28-1.66)$ & $59(35)$ & $14(26)$ & $1.50(0.75-2.97)$ \\
\hline 2-comorbidties (N, \%) & $59(24)$ & $31(32)$ & $0.67(0.40-1.12)$ & $13(20)$ & $13(33)$ & $0.51(0.21-1.26)$ & $42(25)$ & $16(30)$ & $0.76(0.39-1.51)$ \\
\hline 3-comorbidties ( $\mathrm{N}, \%)$ & $33(13)$ & $11(11)$ & $1.20(0.58-2.50)$ & $7(11)$ & $6(15)$ & $0.68(0.21-2.18)$ & $26(15)$ & $4(8)$ & $2.23(0.74-6.70)$ \\
\hline 4-comorbidties (N, \%) & $20(8.0)$ & $4(4.0)$ & $2.04(0.68-6.14)$ & $5(8)$ & $0(0)$ & $7.30(0.39-136)$ & $14(8)$ & $4(8)$ & $1.11(0.35-3.52)$ \\
\hline 5-comorbidties (N, \%) & $4(2.0)$ & $1(1.0)$ & $1.60(0.17-14.3)$ & $1(2)$ & $0(0)$ & $1.87(0.07-47.0)$ & $2(1)$ & $1(2)$ & $0.62(0.06-7.01)$ \\
\hline
\end{tabular}

OR Odds ratio, 95\% Cl 95\% confidence interval, COPD Chronic obstructive pulmonary disease

${ }^{a}$ Other cardiovascular disease: Atrial fibrillation and Heart failure

${ }^{\text {b} T h y r o i d ~ d i s e a s e s: ~ h y p o-/ h y p e r t h y r o i d i s m ~}$

after smoking cessation. This seems to identify a specific risk group which could be a target for screenings for early diagnosis.

The subjects included in this cohort suffered from a mild to moderate IPF. This was reflected by the mean lung function variables presented, such as the mean values of $\mathrm{FVC} \%$ and diffusing capacity for carbon monoxide, \% of predicted (DLCO\%). The patients also had a markedly reduced TLC\% (Table 3 ).

Gender is considered an important determinant of outcome in IPF, according to the GAP- index (Gender- Age- Physiology) [11], but it is still poorly characterized which the factors behind this prognostic difference among male and female are. Female patients have a higher $\mathrm{FVC} \%$ and $\mathrm{TLC} \%$ than males at inclusion. Notably, the differences were also observed in ex- smokers, where females also presented a higher DLCO\%. The higher frequency of ex- smokers among males and the significant difference in pack years might be an explanation to this. No significant differences in lung function were found in never- smokers, further strengthening the notion of cigarette smoking as one of the most important risk factors for the disease and its prognosis.

Table 5 Multivariate analysis of K-BILD total score in total group, male and female patients, respectively

\begin{tabular}{|c|c|c|c|c|c|c|c|c|c|c|c|c|}
\hline & \multicolumn{2}{|c|}{ Total, $N=240$} & \multirow[b]{2}{*}{$P$-value } & \multirow[b]{2}{*}{$95 \% \mathrm{Cl}$} & \multicolumn{2}{|c|}{ Males $N=165$} & \multirow[b]{2}{*}{$P$-value } & \multirow[b]{2}{*}{$95 \% \mathrm{Cl}$} & \multicolumn{2}{|c|}{ Females $N=74$} & \multirow[b]{2}{*}{$P$-value } & \multirow[b]{2}{*}{$95 \% \mathrm{Cl}$} \\
\hline & $\overline{\text { Beta }}$ & SE & & & Beta & SE & & & Beta & SE & & \\
\hline Age & -0.024 & 0.096 & 0.804 & $-0.213-0.165$ & -0.062 & 0.116 & 0.595 & $-0.291-0.167$ & 0.016 & 0.182 & 0.929 & $-0.347-0.380$ \\
\hline BMI & -0.063 & 0.171 & 0.714 & $-0.401-0.275$ & -0.307 & 0.246 & 0.214 & $-0.793-0.179$ & 0.178 & 0.235 & 0.451 & $-0.291-0.648$ \\
\hline Gender & -0.765 & 1.53 & 0.618 & $-3.779-2.250$ & - & - & - & - & - & - & - & - \\
\hline FVC \% predicted & 0.225 & 0.084 & $0.008^{*}$ & $0.060-0.389$ & 0.246 & 0.107 & $0.023^{*}$ & $0.034-0.458$ & 0.191 & 0.138 & 0.169 & $-0.083-0.466$ \\
\hline FEV1\% predicted & -0.03 & 0.078 & 0.699 & $-0.184-0.124$ & -0.047 & 0.095 & 0.618 & $-0.234-0.140$ & -0.02 & 0.143 & 0.889 & $-0.305-0.265$ \\
\hline Comorbidities status & -0.7 & 0.546 & 0.201 & $-1.775-0.375$ & -0.865 & 0.647 & 0.183 & $-2.144-0.413$ & 0.06 & 1.052 & 0.955 & $-2.038-2.158$ \\
\hline
\end{tabular}

$B M I$ Body Mass Index, FVC\% forced vital capacity, \% of expected, FEV1\% forced expiratory volume in first second, \% of expected ${ }^{*} p<0.05$ 
Furthermore, the study presents the first data on the prevalence of comorbidities among Swedish patients with IPF. Cardiovascular diseases, arterial hypertension, gastroesophageal reflux and diabetes mellitus were the most frequent comorbidities in our cohort. The existence of concurrent diseases aside from IPF, such as cardiovascular disease, could be due to shared predisposing risk factors such as smoking and ageing. These results are comparable to what has been observed in cohorts of other registry- based studies and publications [6, 15-18]. Previous studies have also shown that cardiovascular diseases are more frequent in patients with IPF [18] as well as other ILDs [19] compared to matched controls.

The lower prevalence of COPD and asthma in the cohort compared to other published cohorts $[15,20]$ may be due to a low use of spirometry in primary care in Sweden [21, 22]. This is likely to reduce the rate of "physician- based" diagnoses of COPD or asthma (without documented spirometry showing airflow limitation) in the general population. Interestingly, females reported a previous diagnosis of asthma 5 times more often than males. It is unclear if this finding reflects a true higher prevalence of asthma in this group, or if early symptoms of IPF were interpreted as "asthma-like" problems, considering the lower number of smokers/ex-smokers among females.

Our study showed significant differences in the prevalence of coronary artery disease, other cardiovascular diseases, thyroid related diseases and osteoporosis between the genders. In addition, almost $80 \%$ of patients suffer from one or more comorbid disease. Further studies are needed in order to understand the impact of comorbidities on the course of the disease, e.g. on mortality and survival, QoL and symptoms burden in this cohort. However, studies conducted on the Australian IPF registry (AIPFR) [15] and the German INSIGHTS- IPF [20] have already provided us with some insight into the relevance and influence of comorbidities in IPF. While analyses on survival on the Australian cohort showed no effect on outcome, the cohort in Germany, where almost $90 \%$ of patients had one or more comorbidity, showed that the number of comorbidities were associated with mortality. A recent Danish study [19] on comorbidities and mortality in patients with ILDs, showed a significant difference in the frequency of comorbidities and mortality compared to age and gender matched non- ILD controls.

Idiopathic pulmonary fibrosis is known to impair quality of life [23-26]. Our study did not find any significant difference in QoL between genders in terms of K- BILD total score and its domains in the total cohort and in exsmokers although females presented a more preserved lung function. One reason could be that the questionnaire used in our study (K-BILD) is not sufficiently sensitive to detect differences among males and females. It may also be considered that the way they tend to perceive the disease and their quality-of-life $(\mathrm{QoL})$ is influenced by IPF in different ways. In particular, dyspnea seems to negatively influence physical effort capacity in males, whilst it influences the emotional sphere to a larger extent in females [27]. Interestingly, female neversmokers responded worse on the domain of chest symptoms compared to males. However, the group numbers were relatively small and the result should be interpreted with caution. Perhaps, in females, QoL is impaired earlier during the course of the disease, leading to an earlier diagnosis. This question will need be addressed in future studies.

Furthermore, K- BILD total score was shown to be influenced by $\mathrm{FVC} \%$, i.e. a higher value of $\mathrm{FVC} \%$ was associated with higher total score in males but not in females. In a comparison study [28] of the generic health related quality of life (HRQL) questionnaire EuroQol 5Dimensional 5- Level (EQ-5D-5 L) and the more ILDspecific K-BILD, regression analysis of impact factors on EQ-5D-5 L and K-BILD results showed similar results on $\mathrm{FVC} \%$ ' influence on all measures.

Our study has some limitations: First, the data on comorbidities were self- reported by the patients and not instrumentally confirmed, which may result in underreporting. This is a common problem when conducting research on registry- data $[15,20]$. Secondly, as data is collected from patients' routine clinical care from different centers around the country, this might result in variability in the procedures performed. For example, some centers perform a $6 \mathrm{MWT}$ and body plethysmography (TLC) more routinely than others.

To date, the information on the impact of treatment of IPF and comorbidities on the course of the disease in males and females, is still lacking, and further research is needed. Moreover, differences in QoL and mortality are poorly explored. Recent studies suggested that optimal management of reflux [29] and sleep apnea may influence the course of IPF [30]. It is likely that instrumental screening of comorbidities soon will become mandatory due to the potential impact of new interventions on survival. Nonetheless, comorbidities in IPF is currently treated as in non- IPF patients, and knowledge about their prevalence is important in order to provide best care and maybe also tailored interventions in consideration of differences on the basis of gender.

\section{Conclusion}

Females have a more preserved lung function than male patients at presentation, while the prevalence of cardiovascular diseases such as coronary heart disease is in increased in males despite smoking history and atrial fibrillation and heart failure in ex-smokers. Meanwhile gastroesophageal reflux and asthma is increased in 
female never- smokers and thyroid diseases in female ex- smokers. IPF seems to influence quality of life measured with K-BILD differently between the genders, with chest symptoms being more frequent in female neversmokers compared to males. Additional longitudinal research on larger patient cohorts exploring these phenotypic differences are needed in order to elucidate the potential need for tailored therapeutic interventions and overall care on the basis of gender.

\begin{abstract}
Abbreviations
6MWT: 6- min walking test; BMI: Body mass index; COPD: Chronic obstructive pulmonary disease; DLCO\%: Diffusing capacity of carbon monoxide, \% of predicted; FEV $\%$ : Forced expiratory volume, $\%$ of predicted; FVC\%: Forced vital capacity, \% of predicted; GAP: Gender age physiology; HRQL: Health related quality of life; IIP: Interstitial idiopathic pneumonia; ILD: Interstitial lung disease; IPF: Idiopathic pulmonary fibrosis; K- BILD: King's Brief Interstitial Lung Disease; QoL: Quality of life; TLC\%: Total lung capacity, \% of predicted; UIP: Usual interstitial pneumonia
\end{abstract}

\section{Acknowledgements}

The Swedish IPF Registry was funded with grants from the Swedish Heart and Lung Foundation (Hjärt- Lungfonden), Paul and Ragna Nyberg Foundation, Karolinska Institutet, Boehringer Ingelheim, Roche, and with the support from the Karolinska University Hospital.

Special thanks to Prof Surinder Birring, King's College London, London, UK, for his support with the K-BILD questionnaire.

We would like to thank all participants and physicians, study nurses and other clinical staff that are involved and contribute to the registry: Lena Aldenstam, Anne-Marie Andersson, Lars Andersson, Holger Becker, Alexander Bengtsson, Synnöve Bergentz, Christel Bergström, Anna Berséus, Helene Blomqvist, Kärstin Byström, Cristina Cretu, Margitha Dahl, Fredrik Dejby, Jonas Einarsson, Gunnel de Forest, Kristina Forsberg, Ingrid Gerhardsson, Lena Granbom, Christel Hannus, Kirsten Johansson, Helena Jonsson, Carl-Axel Karlsson, Eva-Marie Karlsson, Sara Klänge, Lise-Lotte Landenfelt Gestré, Leo Lazer, Håkan Lindberg, Carina Lundberg, Carina Modén, Pernilla Munthe-Granlund, Lennart Nilholm, Kenneth Nilsson, Marina Nilsson, Rikard Nilsson, Lina Niska, Cecilia Olivesten, Shumi Omar, Andreas Palm, Bo Pedersen, Lennart Persson Anders Pettersson, Birgitta Pettersson, Olga Pettersson, Ewa Petterstedt, Anders Planck, Camilla Regnér, Rolf Rosin, Henrik Ryftenius, Pierre Sobrino, Jan Starlander, Senada Suljanovic, Emma Sundström, Anna Svensson, Camilla Thall, Anders Thylen, Pia Wallin, Ulla Waxne, Valentyna Yasinska, Milena Ymefors. The Swedish IPF registry is currently collecting data from the following hospitals: Karolinska University hospital, Skaraborgs hospital Skövde, Central hospital Kristianstad, Falun hospital, University hospital of Umeå, Sunderby hospital, Linköping university hospital, Uppsala university hospital, Gävle hospital, Östersund hospital, Skåne university hospital, NU hospital Trollhättan, Danderyd hospital, Sahlgrenska university hospital, Ängelholm hospital, Lindesberg hospital, Helsingborg hospital, Örebro university hospital, Höglands hospital Eksjö, Blekinge hospital Karlshamn, Ystad hospital, Trelleborg hospital.

\section{Authors' contributions}

DK extracted the data, performed the statistical analyses and prepared the draft of the manuscript. JG was involved in statistical analysis and in drafting of the manuscript. IP was involved in the data collection, interpretation of the results and in drafting the manuscript. $L C$ was involved in the data collection, interpretation of the results and in drafting the manuscript. MS was involved in the data collection, interpretation of the results and in drafting the manuscript. GF was involved in the design of study, collection of data, statistical analysis, interpretation of the results and drafting of the manuscript. All authors participated in the preparation and approval of the final manuscript

\section{Funding}

The Swedish IPF- registry has received funding from the Swedish Heart and Lung Foundation, Boehringer Ingelheim and Roche. The design of the study, data analyses, interpretation of results and writing was performed by the authors of the manuscript without input from the funding bodies.

\section{Availability of data and materials}

Data supporting the findings of this study are available from the corresponding authors (DK, GF) on reasonable request. The data are not publicly available due to the containment of information that could compromise research participant consent.

\section{Ethics approval and consent to participate}

The study was conducted under the approval of the Stockholm's Regional Ethical Committee (Ref No. 2014/1202-31/4 and Ref No. 2018/1449-31/1). Patients are asked to sign an informed consent upon inclusion in the registry.

\section{Consent for publication}

Not applicable.

\section{Competing interests}

DK and JG reports no conflict of interest. IP received fees for lectures from Boehringer Ingelheim and Roche. LC received fees for lectures from Boehringer Ingelheim and Roche. MS received fees for lectures and consulting from Boehringer Ingelheim and Roche. GF received fees for lectures from Boehringer Ingelheim and Roche.

Received: 23 April 2019 Accepted: 14 November 2019

Published online: 27 November 2019

References

1. Raghu G, Collard HR, Egan JJ, Martinez FJ, Behr J, Brown KK, et al. An official ATS/ERS/JRS/ALAT statement: idiopathic pulmonary fibrosis: evidence-based guidelines for diagnosis and management. Am J Respir Crit Care Med. 2011; 183(6):788-824.

2. Richeldi L, Collard HR, Jones MG. Idiopathic pulmonary fibrosis. Lancet. 2017;389(10082):1941-52.

3. Fernández Pérez ER, Daniels CE, Schroeder DR, St Sauver J, Hartman TE, Bartholmai BJ, et al. Incidence, prevalence, and clinical course of idiopathic pulmonary fibrosis: a population-based study. Chest. 2010;137(1):129-37.

4. Raghu G, Chen S-Y, Hou Q, Yeh W-S, Collard HR. Incidence and prevalence of idiopathic pulmonary fibrosis in US adults 18-64 years old. Eur Respir J. 2016:48(1):179-86

5. Strongman $\mathrm{H}$, Kausar I, Maher TM. Incidence, prevalence, and survival of patients with idiopathic pulmonary fibrosis in the UK. Adv Ther. 2018;35: 724-736.

6. Raghu G, Amatto VC, Behr J, Stowasser S. Comorbidities in idiopathic pulmonary fibrosis patients: a systematic literature review. Eur Respir J. 2015; 46(4):1113-30

7. Panos RJ, Mortenson RL, Niccoli SA, King TE. Clinical deterioration in patients with idiopathic pulmonary fibrosis: causes and assessment. Am J Med. 1990;88(4):396-404.

8. Kärkkäinen M, Nurmi H, Kettunen H-P, Selander T, Purokivi M, Kaarteenaho R. Underlying and immediate causes of death in patients with idiopathic pulmonary fibrosis. BMC Pulm Med. 2018;18(1):69.

9. Tsiligianni I, Rodríguez MR, Lisspers K, LeeTan T, Infantino A. Call to action: improving primary care for women with COPD. NPJ Prim Care Respir Med. 2017;27(1) [cited 2018 Aug 2]. Available from: http://www.nature.com/ articles/s41533-017-0013-2.

10. Isla D, Majem M, Viñolas N, Artal A, Blasco A, Felip E, et al. A consensus statement on the gender perspective in lung cancer. Clin Transl Oncol. 2017;19(5):527-35.

11. Ley B, Ryerson CJ, Vittinghoff E, Ryu JH, Tomassetti S, Lee JS, et al. A multidimensional index and staging system for idiopathic pulmonary fibrosis. Ann Intern Med. 2012;156(10):684-91.

12. Cordier J-F, Cottin V. Neglected evidence in idiopathic pulmonary fibrosis: from history to earlier diagnosis. Eur Respir J. 2013;42(4):916-23.

13. Patel AS, Siegert RJ, Brignall K, Gordon P, Steer $S$, Desai SR, et al. The development and validation of the King's Brief Interstitial Lung Disease (K-BILD) health status questionnaire. Thorax. 2012;67(9):804-10.

14. Svensk Lungmedicinsk Förening. Vårdprogram för idiopatisk lungfibros [Internet]. 2019. [cited 2019 Mar 25]. Available from: http://sImf.se/ wpcontent/uploads/2019/03/vp_ipf_19 web.pdf. ISBN: 978-91-87514-47-0.

15. Jo HE, Glaspole I, Grainge C, Goh N, Hopkins PMA, Moodley Y, et al. Baseline characteristics of idiopathic pulmonary fibrosis: analysis from the Australian Idiopathic Pulmonary Fibrosis Registry. Eur Respir J. 2017:49(2):1601592. 
16. Behr J, Kreuter M, Hoeper MM, Wirtz H, Klotsche J, Koschel D, et al. Management of patients with idiopathic pulmonary fibrosis in clinical practice: the INSIGHTS-IPF registry. Eur Respir J. 2015;46(1):186-96.

17. Guler S, Zumstein P, Berezowska S, Pöllinger A, Geiser T, Funke-Chambour M. Idiopathic pulmonary fibrosis in a Swiss interstitial lung disease reference centre. Swiss Med Wkly. 2018;148:w14577.

18. Dalleywater W, Powell HA, Hubbard RB, Navaratnam V. Risk factors for cardiovascular disease in people with idiopathic pulmonary fibrosis: a population-based study. Chest. 2015;147(1):150-6.

19. Hilberg O, Bendstrup E, Løkke A, lbsen R, Fløe A, Hyldgaard C. Co-morbidity and mortality among patients with interstitial lung diseases: a population-based study. Respirol Carlton Vic. 2018;23(6):606-12.

20. Kreuter M, Ehlers-Tenenbaum S, Palmowski K, Bruhwyler J, Oltmanns U, Muley T, et al. Impact of comorbidities on mortality in patients with idiopathic pulmonary fibrosis. PLoS One. 2016:11(3):e0151425.

21. Lisspers K, Ställberg B, Hasselgren M, Johansson G, Svärdsudd K. Organisation of asthma care in primary health care in mid-Sweden. Prim Care Respir J J Gen Pract Airw Group. 2005;14(3):147-53.

22. Hasselgren $M$, Arne M, Lindahl A. Estimated prevalences of respiratory symptoms, asthma and chronic obstructive pulmonary disease related to detection rate in primary health care. Scand J Prim Health Care. 2001;19(1):54-7.

23. De Vries J, Kessels BL, Drent M. Quality of life of idiopathic pulmonary fibrosis patients. Eur Respir J. 2001;17(5):954-61.

24. Tomioka H, Imanaka K, Hashimoto K, Iwasaki H. Health-related quality of life in patients with idiopathic pulmonary fibrosis--cross-sectional and longitudinal study. Intern Med Tokyo Jpn. 2007:46(18):1533-42.

25. Ferrara G, Carlson L, Palm A, Einarsson J, Olivesten C, Sköld M. Idiopathic pulmonary fibrosis in Sweden: report from the first year of activity of the Swedish IPF-registry. Eur Clin Respir J. 2016;3:31090.

26. Kreuter M, Swigris J, Pittrow D, Geier S, Klotsche J, Prasse A, et al. Health related quality of life in patients with idiopathic pulmonary fibrosis in clinical practice: insights-IPF registry. Respir Res. 2017;18(1):139.

27. Han MK, Swigris J, Liu L, Bartholmai B, Murray S, Giardino N, et al. Gender influences health-related quality of life in IPF. Respir Med. 2010;104(5):724-30

28. Szentes BL, Kreuter M, Bahmer T, Birring SS, Claussen M, Waelscher J, et al. Quality of life assessment in interstitial lung diseases:a comparison of the disease-specific K-BILD with the generic EQ-5D-5L. Respir Res. 2018;19(1):101.

29. Raghu G, Pellegrini CA, Yow E, Flaherty KR, Meyer K, Noth I, et al. Laparoscopic anti-reflux surgery for the treatment of idiopathic pulmonary fibrosis (WRAP-IPF): a multicentre, randomised, controlled phase 2 trial. Lancet Respir Med. 2018;6:707-14.

30. Gille T, Didier M, Boubaya M, Moya L, Sutton A, Carton Z, et al. Obstructive sleep apnoea and related comorbidities in incident idiopathic pulmonary fibrosis. Eur Respir J. 2017:49:1601934.

\section{Publisher's Note}

Springer Nature remains neutral with regard to jurisdictional claims in published maps and institutional affiliations.

Ready to submit your research? Choose BMC and benefit from:

- fast, convenient online submission

- thorough peer review by experienced researchers in your field

- rapid publication on acceptance

- support for research data, including large and complex data types

- gold Open Access which fosters wider collaboration and increased citations

- maximum visibility for your research: over $100 \mathrm{M}$ website views per year

At $\mathrm{BMC}$, research is always in progress.

Learn more biomedcentral.com/submissions 